\title{
Influence of Air Quality Conditions on Asthmatic Patient Visits in Kuwait
}

\section{Sabbah I', Nermina Arifhodzic ${ }^{2}$, Mona Al-Ahmad ${ }^{2}$, Ali Al-Enizi ${ }^{2}$, Aneesah Al-Haddad ${ }^{1}$ and Nada Al-Ajmi ${ }^{1}$}

${ }^{1}$ Department of Natural Sciences, College of Health Sciences, the Public Authority for Applied Education and Training, Kuwait ${ }^{2}$ Al Rashed Allergy Centre, Ministry of Health, Kuwait

\begin{abstract}
Background: Few studies have investigated the relationship between air quality and asthma in Kuwait. However there is still a lacking in the observations and methodology to precisely analyze the data.

Objective: We aim to investigate the relationship of pollen count, weather conditions and air pollutants to the number of visits for asthma in Kuwait.

Methods: The daily number of adult visits for symptomatic asthmatic patients to Al-Rasheed Allergy Centre in Kuwait has been recorded during the entire year of 2012. Pollen counts are obtained from the same Center. The method of superposed epoch (Chree analysis) has been used to study the behavior of weather parameters and air pollutants on the days with high number of patients.

Results: A good correlation ( $r=0.51)$ is obtained between airborne pollens and asthmatic patients. We identify 35 days in 2012 with high number of asthma patients. The wind speed increases one day before the increase in the numbers of asthmatic patients. The relative humidity increases with the number of asthmatic patients while the visibility decreases. In general we find no link between air pollutants and the number of asthmatic patients. The major dust storms of 2012 have no effect on the number of asthmatic patients.

Conclusions: The pattern of the pollen counts is persistent; it exhibits a consistent annual cycle. The local pollens play the major role in significant asthma development. The increase in wind speed helps to spread the pollens in air and consequently increase the number of patients. The increase in relative humidity may trigger asthmatic symptoms. In general we find no direct association between the number of asthmatic patients and levels of air pollutants or dust storms. More convincing epidemiology data are needed, to causally confirm relationship between air quality and asthma in our environment.
\end{abstract}

Keywords: Air quality; Pollen; Asthma; Air pollutants; $\mathrm{PM}_{25} ; \mathrm{Hu}-$ midity; Superposed epoch analysis

\section{Introduction}

Asthma is one of the most common chronic inflammatory diseases, characterized by hyper reactivity of the airways and it is triggered by different stimuli. In genetically susceptible people, environmental factors play attributable risk for asthma and allergy development $[1,2]$. Reports from different geographical areas document air quality condition, as being an important asthma exacerbation trigger. Kuwait is a subtropical desert located in the Arabian Peninsula. Dust and dust storms form a major feature of this region in addition to its arid climate (extreme heat, low humidity and very little precipitation) [3]. The Arabian Peninsula has one of the most difficult environments in the world to characterize, monitor and climate model. It is considered as having the largest confluence of dust and anthropogenic emission in the world [3]. In Kuwait the prevalence of physician-diagnosed asthma is estimated to be about $15 \%$ in adults and $18 \%$ in children [4]. Numerous studies pointed out common association between exposure to pollen allergens and asthma symptoms [5,6]. Pollen allergy is frequently used to assess the relationship between air quality and asthma [7-10]. Several studies have demonstrated an association between air pollutants and asthma exacerbation $[11,12]$. The relation between asthma emergency calls and weather parameters was observed during the 10 years period (2002-2011) in Italy [13]. They found that wind speed and air pollutants significantly diminished during the pick of calls. Moreover, they got significant parabolic trends over the months for dew point, temperature, humidity and the wind speed. DapulHidalgo and Bielory [14] and Delamater et al. [15] found no consensus regarding impact of weather variable on asthma. A few investigators have studied the impact of air quality and weather conditions on asthma symptoms in the Middle East. Qasem et al. [16] obtained an inverse correlation $(\mathrm{r}=-0.52)$ between wind speed and asthma visits to Kuwait Allergy Centre during 2003. They also found no significant correlation $(\mathrm{r}=0.34)$ with pollen counts. Contrary, Behbehani et al. [17] obtained a good correlation between pollen counts and the number of patients diagnosed with allergic rhinitis at Kuwait Allergy Centre during the time interval of 1996-2000. The prevalence of asthma has risen in industrialized countries, and most epidemiologic studies focus on possible causalities between air pollution and respiratory allergic diseases. Dust particles reach as far as the inside of the nose, mouth or throat. However smaller or fine, particles can get deeper into the lungs, increasing the potential of seriously harming people's health. Thalib and Al-Taiar [18] studied the effect of dust storms on hospital admissions in Kuwait during the interval: 1996-2000. They concluded that, dust storms have a significant impact on respiratory and asthma admissions in Kuwait. The aim of this study is to determine the effect of air quality on the number of asthmatic patients.

\section{Methods}

We recorded the daily adult symptomatic asthmatic patients to

${ }^{*}$ Corresponding author: Ismail Sabbah, Department of Natural Sciences, Faculty of Health Sciences, The Public Authority for Applied Education and Training, Kuwait, Tel: 96597942100; E-mail: sabbahsom@yahoo.com

Received August 22, 2014; Accepted November 07, 2014; Published November 17,2014

Citation: Sabbah I, Arifhodzic N, Al-Ahmad MS, Al-Enizi A, Al-Haddad A, et al. (2014) Influence of Air Quality Conditions on Asthmatic Patient Visits in Kuwait. J Allergy Ther 5: 197. doi:10.4172/2155-6121.1000197

Copyright: @ 2014 Sabbah I, et al. This is an open-access article distributed unde the terms of the Creative Commons Attribution License, which permits unrestricted use, distribution, and reproduction in any medium, provided the original author and source are credited. 
Al-Rasheed Allergy Centre in Kuwait during the entire year of 2012. Al-Rasheed Center is the only tertiary center for asthma and allergic diseases in Kuwait. Patients diagnosed with asthma (GINA) are treated and followed up in the Respiratory Unit of the Center. Patients with other chronic diseases have been excluded. 7-9 days collection of the pollen counts was obtained from the Air biology laboratory in the same Center. The monitoring station is located on the flat roof of the Center, at the proper height, suitable for the most important allergenic flora available in Kuwait (grass and weed). The Burkard 7-days volumetric spore trap was used for the collection of the air sample. The monitoring operates on the principle of impaction through suction with $2 \mathrm{~mm}$ clockwise movement on the drum each hour (a slit at a rate of $10 \mathrm{l} /$ min). Recording tape was collected weekly. Deposit on the tape was attached to the microscope slide, covered with Glycerin, stained and then counted under light microscope using standard sampling procedure. The daily weather parameters, namely: Temperature (Temp), visibility (Vis), wind speed (V), dew point (Dew), relative humidity (R.H) and diurnal temperature range (the difference between the daily maximum and minimum temperature) are acquired from the National Oceanic and Atmospheric Administration (NOAA). Daily values of air pollutants included: nitrogen oxides (NOx), ozone $\left(\mathrm{O}_{3}\right)$, sulfur dioxide $\left(\mathrm{SO}_{2}\right)$, carbon monoxide $(\mathrm{CO})$, carbon dioxide $\left(\mathrm{CO}_{2}\right)$, methane $\left(\mathrm{CH}_{4}\right)$ and particular matter $\left(\mathrm{PM}_{10}\right)$ which includes all particles with radii $\leq 5 \mu \mathrm{m}$, obtained from Kuwait Environment Public Authority (EPA) are used in this analysis. We use these parameters to determine the influence of climatic condition and air pollutants on the numbers of asthmatic patients. The HYSPLIT (Hybrid Single-Particle Lagrangian Integrated Trajectory) model from NOAA was used to calculate the back wind trajectories during the day with the highest number of patients during the entire year. Finally we use the method of superposed epochs (Chree analysis) [19] to study the behavior of weather parameters, and air pollutants on and around the days with a high number of patients.

\section{Results}

\section{A link between air pollen counts and the number of asthmatic patients}

Figure 1 shows the daily variation of the total number of visits to $\mathrm{Al}$ Rashid Allergy Center (dotted line) and of the number of symptomatic asthmatic patients (solid line). We got 31286 symptomatic asthmatic patients out of 40760 visits during the entire year. These symptomatic patients are 15 and above years of age, both gender. There is a clear sign of seasonality. The number of patients diagnosed with symptomatic asthma was highest in March-April, September-October and December. The minimal number of cases occurred in May-July. The dashed lines in Figure 2 represent the variation in the 7-9 days averages of the pollen counts. Two seasonal peaks are evident: the main one in autumn and a second twin peaks in spring. A linear increase in the number of patients is shown in September-October during the ascending phase of the autumn peak. The minimal pollen count occurred in May-July. The solid line in Figure 2b illustrates the 7-9 days averages of asthmatic patients in order to compare with the 7-9 days averages of pollen counts. We see that the number of asthmatic patients was high, and track the pollen counts very well during February-April and SeptemberOctober. The number of patients was lowest in May-July, when the pollen counts was the lowest. We got a significant correlation $(\mathrm{p}<0.001$, $\mathrm{r}=0.51$ ) between the 7-9 days averages of asthmatic patient's and the pollen counts. The highest number of daily asthmatic patients during the entire year is represented by star in Figure 2a. This number (244) occurs on April 18, when the pollen count reaches 392 grains $/ \mathrm{m}^{3}$ during

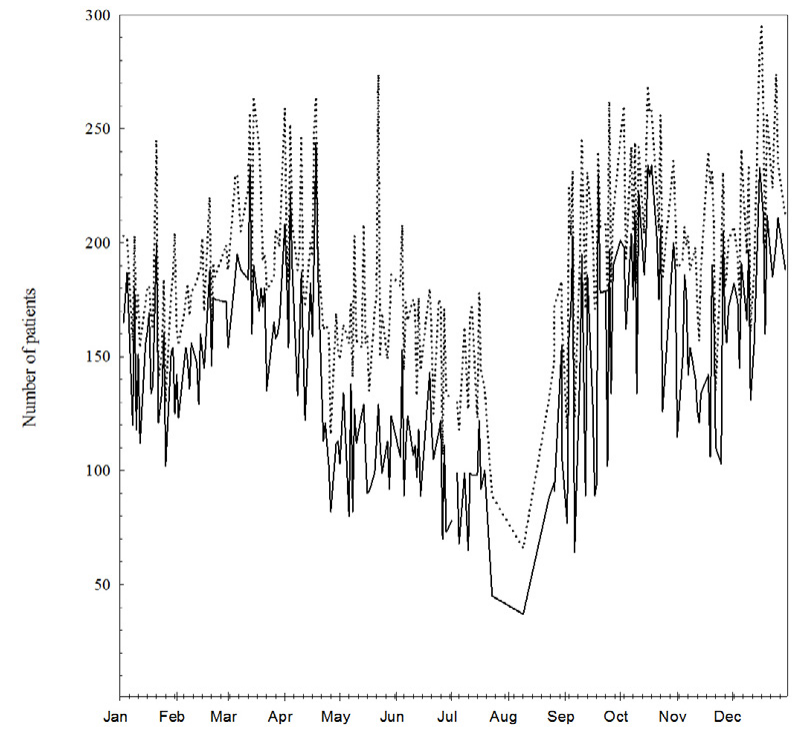

Figure 1: Daily variation of total number of visits to Al-Rashid Allergy Center (dotted line) and of the number of asthmatic patients (solid line). See the seasonal variation.

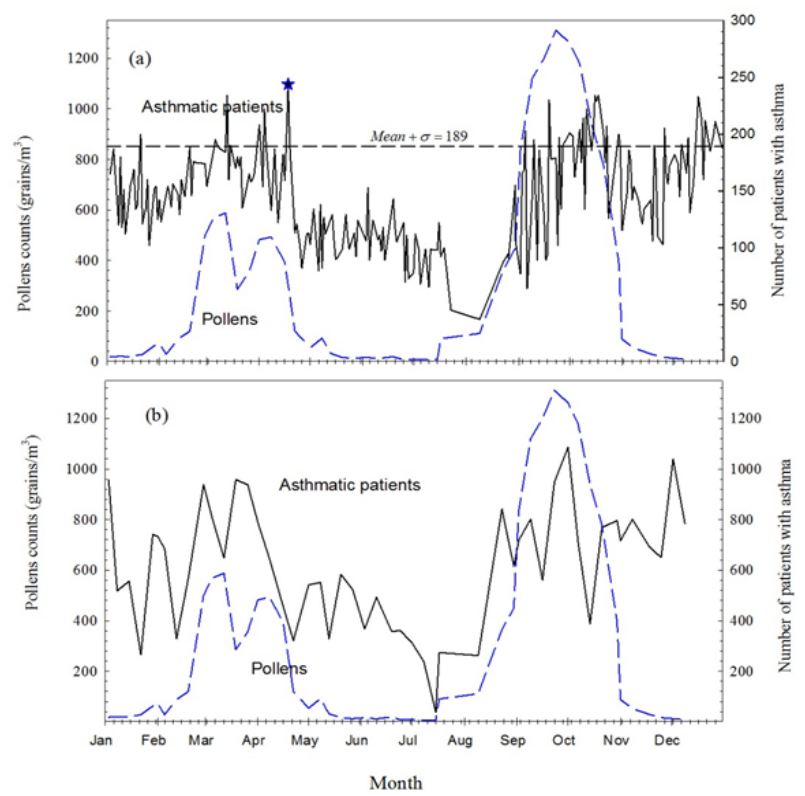

Figure 2: Time variation of 7-9 day averages of the pollen count (dashed line). Note that the main peak occurs in autumn and the a second twin peaks occurs in spring. (a) Daily variation of the number of asthmatic patients (solid line) The dashed horizontal lines represnt 189 patients, (b) Time variation of 7-9 day averages of the number of asthmatic patients ((solid line) for comparison with pollen counts.

the descending phase of the spring peak. The wind speed increases to $6.1 \mathrm{~m} / \mathrm{s}$ in this day. That was the highest wind speed ever recorded during the entire month. The mean daily value of $\mathrm{PM}_{10}$ reaches 646 $\mu \mathrm{g} / \mathrm{m}^{3}$. The wind directions on April 18 are north-westerly (see Figure 1 in the appendix). This indicates that the increase in north-westerly wind speed causes a spread in the air pollens that directly increases the number of patients. The lowest number of asthmatic patients 
(37) occurs on August 9 when the pollen count was low (24 grains/ $\mathrm{m}^{3}$ ). Figure 3 compares the variation of the Volume Size Distributions (VSDs) as a function of the particle geometric mean radius [38] during March 13, with a high number of patients (234), and in August 9 with a minimum number of patients (37). The wind speed increased up to $9.2 \mathrm{~m} / \mathrm{s}$ on March 13, VSD is calculated from Aerosol Optical Depth (AOD) collected by the Aerosol Robotic Network (AERONET) site in Kuwait. Note that we used 13 March, instead of 18 April with the highest number of patients, because there was no AOD observations on 18 April at Kuwait's AERONET site. AOD is a measure of aerosol "column burden" relevant to the needs the air quality community [20]. Note that the pollen counts we use are measured at ground level while VSD represents the concentration of aerosol in the entire column of the atmosphere. We see that the concentration of VSD peaks at geometric mean radius $\mathrm{R} \sim 2.2 \mu \mathrm{m}$. This radius includes coarse aerosol particles (dust, pollen and sea salt). However we cannot distinguish between these types of particles. The peak of particle concentration on 13 March is 10 times that on 9 August. Figure $3 b$ focus on the anthropogenic fine particulate matters $\left(\mathrm{PM}_{2.5}\right.$, which includes all particles with radii $\leq 1.25$ $\mu \mathrm{m})$ released from the burning of fossil fuel and petrochemical industry. These fine particles are real killer as they are invisible and can penetrate into the deepest parts of the lungs causing serious health problems. We see that the VSD of $\mathrm{PM}_{25}$ is much higher on 13 March than on 9 August. This concludes that the $13^{\text {th }}$ of March was characterized by high concentration of both $\mathrm{PM}_{25}$ and the coarse particles and as well as higher wind speed.

\section{Response to weather parameters}

In this section we test the influence of weather parameters on the number of asthmatic patients. We use the Chree analysis [19] to study the behaviors of the weather parameters on the days with a high

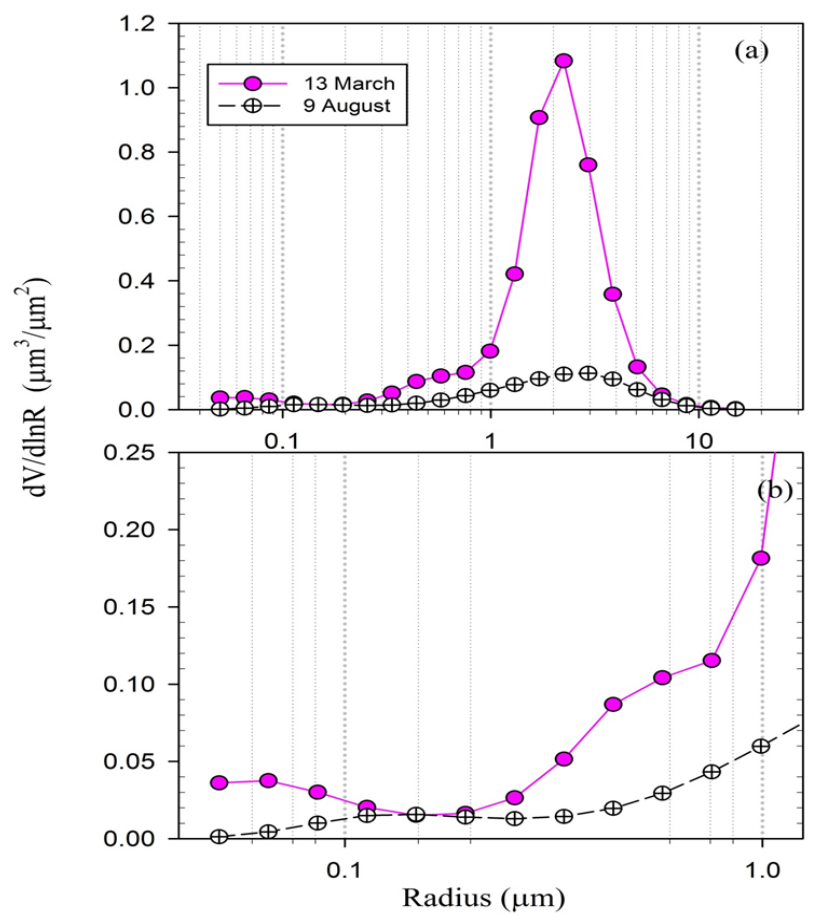

Figure 3: Variation of the volume size distributions during 13 March and 9 August, 2012.

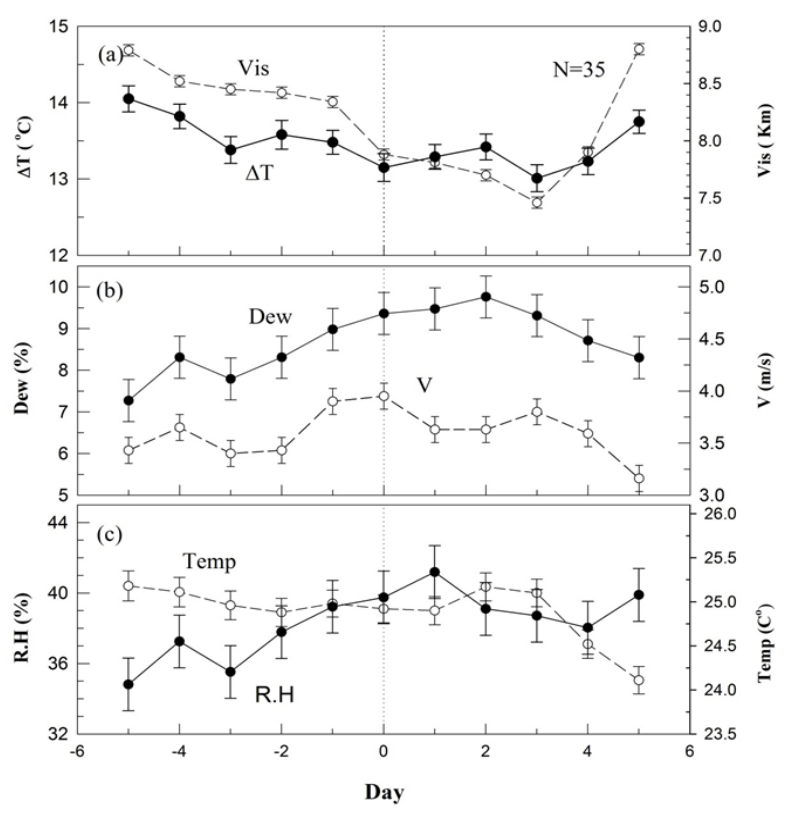

Figure 4: Superposed weather parameters centered on the 35 days with the number of asthmatic patients $\geq 189$. Error bars represent the standard error in each average.

number of asthmatics patients. To construct the superposed epoch we first define the day with a high number of asthmatics patients as the day with number of asthmatics patients that exceeds the average number of asthmatics patients during the entire year plus the associated standard deviation $(146+43)$. We obtain 35 days with the number of asthmatic patients $\geq 189$. This number is considered as a lower limit of the number of asthmatic patients and is represented by the dashed horizontal lines in Figure 2a. We see that the numbers of patients above the dashed lines are mainly in March-April, September-October and December when the pollen count was high. This indicates that the main reason for the increase in the number of asthmatic patients is the increase in the number of pollens. Next we consider these 35 days as key-event days. We first perform the Chree analysis on the visibility. The daily values of the visibility for the key-event days ( 35 days) and background days (331 days) are arranged in a table, with one row for each key-event, and eleven columns containing values of visibility for the 5 days before the key-event day, the key-event day, and the subsequent 5 days, in that order. A comparison between the average values of Vis on the key-event column and background ten columns can be pictured as a superposed epoch. The values of these eleven averages are plotted in Figure 4a (open circles connected with dashed lines). Error estimates $(1 \pm \sigma)$ of the average for each column of the 11 epoch columns are calculated from the scatter of the individual deviation. We see a significant decrease in the average values of the visibility on the days with higher patient numbers (the zero-epoch day when the number of asthmatic patients $\geq 189$ ). Similar calculations have been carried out for the rest of the weather parameters. Figure $4 \mathrm{~b}$ shows a significant increase in the average values of wind speed one day before the zero-day. The wind speed increases to $3.9 \pm 0.1 \mathrm{~m} / \mathrm{s}$, one day before the numbers of asthmatic patients increase. A significant increase in dew point and R.H is clear in Figure $4 \mathrm{~b}$ and $4 \mathrm{c}$ at the zeroday. Figure $4 \mathrm{c}$ shows no significant variation in the temperature, on the days with high number of asthmatic patients. The highest DTR 


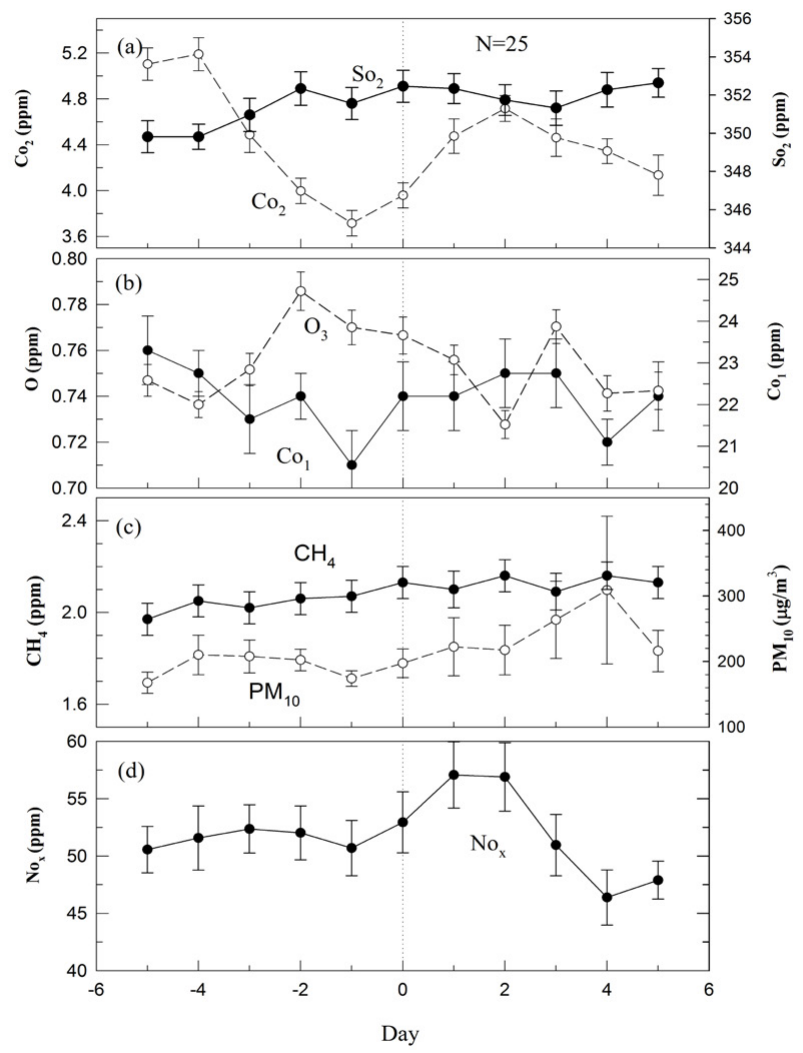

Figure 5: Superposed air pollutants centered on the 25 days with number of asthmatic patient $\geq 189$.

$\left(14^{\circ} \mathrm{C}\right)$ occurs 5 days before the increase in the number of asthmatic patients.

\section{Effect of air pollutants on the number of asthmatic patients}

In this section we applied again the Chree's method to the daily averaged values of air pollutants in order to check if there are any significant variations in air pollutants on the days that have a high number of asthmatic patients. In Figure 5, we plot the averages of the eleven epoch columns for $\mathrm{NOx}, \mathrm{O}_{3}, \mathrm{SO}_{2}, \mathrm{CO}, \mathrm{CO}_{2}, \mathrm{CH}_{4}$ and $\mathrm{PM}_{10}$. We see that both $\mathrm{CO}$ and $\mathrm{CO}_{2}$ get lower averages one day before the increase in the number of asthmatic patients (on the zero-day), while average value of $\mathrm{O}_{3}$ increased two days before the increase in the number of patients. There is no significant change in the daily average values of the other air pollutants on the zero-day.

\section{Effect of dust in patients with asthma}

Here we examine the number of asthmatic patients during major dust storms observed by the Moderate Resolution Imaging Spectroradiometer (MODIS) sensors aboard NASA's Aqua and Terra satellites in 2012. MODIS observed four dust storms on March 17, May 15 , May 24, and June1, 2012. The daily mean values of $\mathrm{PM}_{10}$ for these days are $1350,779,1799$ and $758 \mu \mathrm{g} / \mathrm{m}^{3}$ respectively. Contrary to Thalib and Al-Taiar [18], we find no increase in the number of asthmatic patients during these days. This concludes that dust particles do not have potential effect on asthma.

\section{Discussion}

In order to test the influence of air quality conditions on the number of asthmatic patients in Kuwait; we investigate the link between air pollens, weather parameters, air pollutants, dust storms, and the number of asthmatic patient visits in Al-Rasheed Allergy Centre. We found that the number of asthmatic patients was high and track the pollen counts very well during February-April and September-October and was the lowest in May-July when the pollen count was the lowest. We obtain a significant correlation $(\mathrm{r}=0.51)$ between pollen counts and number of visits for asthma. This concurs the results obtained earlier $[5,8,9,21]$. The shape of our pollen graph is consistent with the results obtained earlier in Kuwait [17,22]. However, spring pollination started a bit earlier in 2012. This earlier start may be due to global changes in climate [12] or to increased concentration in air pollutants [23,24]. We conclude that the pattern of the pollen counts in Kuwait is persistent; it exhibits a consistent annual cycle. Among airborne allergens, local pollens are the leading cause of sensitization (77.3\%) [25]. The most abundant pollens are weed pollens from the families of Chenpodiaceae and Amaranthaceae. They are predominantly spontaneous perennial plants growing on salt-enriched soil. Sensitization to Chenopods in Kuwaiti susceptible people ranges from $64.3 \%$ to $76.7 \%$ [26] followed by Bermuda grass; $38.2 \%$ [26] to $55 \%$ [25]. Short time exposure to a high level of pollen has significant impact to the development of asthma symptoms [5]. On the other hand long exposure to even relatively low levels of weed and grass pollen is associated with increased sensitization and asthma symptoms [6]. The role of relatively low levels of weed and grass pollen in sensitized patients could be important for our region as it is characterized by harsh desert climate, scanty flora, and long pollination seasons. However, it is not clear how the whole pollen grains, with a diameter $\geq 10 \mu \mathrm{m}$, can cause asthma. The lower airway inflammation is not caused by the whole pollen grains, but by pollen starch granules, which are contained in large numbers within the pollen grain [27]. They deposit preferentially in lower airways, because their diameter does exceed $5 \mu \mathrm{m}$. Starch granules are expelled from pollen grains due to rain or morning dew [27]. They contain major pollen allergens which cause immunological reactivity in allergic patients [8]. Plants are a source of many clinically important allergens and are sensitive to climate change, as well as to the increased level of chemical pollutants. Climate changes and weather parameters may affect both pollen production and pollen allergenicity [28], while local weather may influence atmospheric chemical reactions and affect atmospheric transport process. The highest number of asthmatic patients during the entire year occurs on April18, 2012 when the average number of pollen count was high $\left(392\right.$ grains $\left./ \mathrm{m}^{3}\right)$ and wind speed reached the highest speed ever recorded during the entire month. High wind speed increases the spread of airborne pollen and produces a higher distribution of pollen concentration that helps in increasing asthma. Sabbah et al. [3] showed that the wind direction over Kuwait is predominantly northerly and north-westerly flowing from Iraqi deserts, which brings extremely dry air and dust, especially in the spring. Wind speed is closely related to the increased release and dispersion of airborne allergens in the atmosphere. The higher wind speed and the greater leaf shedding may result in a steadier rate of spore dispersal [29]. Figure 3b shows that the concentrations of both coarse and $\mathrm{PM}_{2.5}$ particles on March 13 are higher than those on August 9. The wind speed was also high on March13. This concludes that the higher number of patients on March 13 may be due to the increase in the concentration of anthropogenic $\mathrm{PM}_{2.5}$ and coarse aerosol. These coarse particles may be pollen, dust, or both. We are not sure whether the pollen or $\mathrm{PM}_{2.5}$ was more effective in triggering asthma symptoms on that day.

Using the Chree analysis for the 35 days with the number of 
asthmatic patients exceeds 188; we observe an increase in wind speed one day before the increase in the number of the asthmatic patients. The National Institute of Health guidelines list [30] mentioned "change in weather" as a possible trigger factor for asthma. A significant increase in R.H is observed with the increase of the number of asthmatic patients. Our asthmatic patients consider the humid weather as a powerful trigger for asthma. This agrees with the results obtained by [31]. They found significant impact of interday and intraday change in humidity two days before the examined admission date. Contrary, [32] observed that altitude and annual variation in temperature and R.H are negatively associated with asthma symptoms in children. We also observed a decrease in the visibility with the increasing number of patients. Contrary to the above results, [16] found insignificant correlation $(r=-0.10)$ between the number of patient visits to AlRasheed Allergy Centre and R.H. Moreover they obtained negative correlation $(\mathrm{r}=-0.52)$ between the number of asthmatic patients and wind speed. This contradiction is because we focus on the 35 days with high number of patients, but they correlated the whole set of data. We see from Figure 4a that there is a decrease in the DTR during the days with a high number of adult patients. The highest DTR occurs 5 days before the zero-epoch day. Contrary to our results [33], found that the increase in DTR is associated with an increase in the occurrence of respiratory symptoms for children. Moreover, we find no significant variation in the average values of temperature, on the days with a high number of asthmatic patients. Contrary, Epton et al. [34] found a small association between temperature and peak expiratory flow rate for asthmatic patients in New Zeeland. In addition Delamater et al. [15] documented a significant additional asthma exacerbation when the temperature increases one day before admission, while that association was less associated with the intraday temperature increase. Contrary, Abe et al. [35] got a close association between increased asthma exacerbations, and decreased in the temperature in adult asthmatics. Khwarahm et al. [36] suggested that high temperature and sunshine duration may have a strong positive correlation with the grass pollen counts. These factors may also increase pollen allergenicity [37]. Kuwait has the highest surface temperature in the Arabian peninsula, that may explains the high prevalence of sensitization to the local pollen [26] and development of respiratory allergic diseases in Kuwait. Figure 2 in the appendix displays the time series of the meteorological parameters that have significant variation on or around the days with high number of patients.

The role of air pollutants in determining asthma morbidity has not been well established [23]. Although the daily average values of the air pollutants of the 11 epoch days shown in Figure 5 are quite high, we do not see significant increase in the average value of air pollutants on the zero-epoch day. This may be due to adaptation of human in response to climatic stimuli [39]. Additionally Abe et al. [35] concluded that air pollution does not seem to play a major role in significant asthma exacerbation. Moreover Lewis et al. [40] could not detect any association between ambient air pollution, and asthma-related emergency visits in UK. On the other hand [41], concluded that the current level of urban air pollution may have a lasting effect on lung development in children from ages 10-18 years in the US. Figure 5b shows an increase in the level of $\mathrm{O}_{3}$ two days before the increase in the number of patients (zero-day). This confirms with the multi-pollutant model performed by KO et al. [42] in Hong-Kong. They demonstrated that the increase in the level of $\mathrm{O}_{3}$ is significantly associated with increasing admissions for asthma.

Dust collected in Kuwait in the 1990s was found to cause DNA, and cellular membrane damage [43]. Smaller-size sandstorm dust particles with high adhesive properties have a greater potential of aggravating asthma [44]. Bener et al. [45] identified dust storm exposure as one of the significant predictors of asthma in schoolchildren. Thalib and AlTaiar [18] investigated the effect of dust storms on hospital admissions due to asthma and all respiratory diseases in Kuwait during the interval 1996-2000 was investigated [21]. They defined a dust storm day as a day with mean daily value of $\mathrm{PM}_{10}$ that exceed $200 \mu \mathrm{g} / \mathrm{m}^{3}$. This is a small lower cut off for a dust storm. Consequently, they came up with a huge number of dust storms (569) during their 5-year of study. They concluded that dust storms have a significant impact on respiratory, and asthma admissions in Kuwait. On contrary, we find no significant increase in the mean daily value of $\mathrm{PM}_{10}$ on the days with a high number of asthmatic patients (Figure $5 \mathrm{c}$ ). The daily average values of $\mathrm{PM}_{10}$ during 10 out of the 11 epoch days shown in Figure $5 \mathrm{c}$ equal or exceed the lower cut off defined by [18]. Moreover, contrary to above mentioned study [21], we find no increase in the number of asthmatic patients during the four major dust storms observed by MODIS in 2012. The daily mean average values of $\mathrm{PM}_{10}$ during these storms for these days are much higher than the lower cut off defined by Thalib and Al-Taiar [18]. They found that these storms in Kuwait consist mainly of coarse particles [40]. We conclude that the dust particles do not have potential effect on asthma. Our results finding confirms the results obtained earlier in Australia [46] where no hospital admission due to respiratory problems was recorded during the enormous dust storm of September 2009. They concluded that the heavy dust storm had short-lived impact on hospital admission. Unfortunately we could not perform Chree analysis method to the pollen counts in order to check if there is any time lag between pollen counts and high number of asthmatics patients, since we did not have daily pollen data. In the next study we will extend our investigations to study in more details the effect of fine particulate matters $\left(\mathrm{PM}_{2.5}\right)$ on asthma exacerbations. Recently Kuwait was ranked as number 167 out of 178 countries for air quality because of the high concentration of $\mathrm{PM}_{2.5}$ [47].

\section{Acknowledgment}

We wish to acknowledge EPA for the air pollutants data and NOAA for the weather parameters and for development of the HYSPLIT graphical user interface. This research is partially supported by Kuwait Foundation for the Advancement of Sciences (project 2011-1401-01). I. Sabbah is grateful to Fahd Al-Mulla for valuable discussions. We thank Youmna Sabbah and Nawal Al-Qallaf for technical assistance.

\section{References}

1. Sheffield PE, Weinberger KR, Kinney PL (2011) Climate change, aeroallergens, and pediatric allergic disease. Mt Sinai J Med 78: 78-84.

2. Ueda K, Nitta H, Odajima $\mathrm{H}$ (2010) The effects of weather, air pollutants, and Asian dust on hospitalization for asthma in Fukuoka. Environ Health Prev Med 15: 350-357.

3. Sabbah I, Al-Mudhaf HF, Al-Kandari A, Al-Sharifi F (2012) Remote sensing of desert dust over Kuwait: long-term variation. Atmosph Pollut Res 3: 95-104

4. Khadadah M (2013) The cost of asthma in Kuwait. Med Princ Pract 22: 87-91.

5. Tobías A, Galán I, Banegas JR, Aránguez E (2003) Short term effects of airborne pollen concentrations on asthma epidemic. Thorax 58: 708-710.

6. DellaValle CT, Triche EW, Leaderer BP, Bell ML (2012) Effects of ambient pollen concentrations on frequency and severity of asthma symptoms among asthmatic children. Epidemiology 23: 55-63.

7. Ribeiro H, Oliveira M, Ribeiro N. Cruz A, Ferreiera A (2009) Pollen allergenic potential nature of some trees species: A multidisciplinary approach using aerobiological, immunochemical and hospital admissions data. Environ Res 109: 328-333.

8. Bacsi A, Choudhury BK, Dharajiya N, Sur S, Boldogh I (2006) Subpollen particles: carriers of allergenic proteins and oxidases. J Allergy Clin Immuno 118: $844-850$

9. Héguy L, Garneau M, Goldberg MS, Raphoz M, Guay F, et al. (2008) 
Citation: Sabbah I, Arifhodzic N, Al-Ahmad MS, Al-Enizi A, Al-Haddad A, et al. (2014) Influence of Air Quality Conditions on Asthmatic Patient Visits in Kuwait. J Allergy Ther 5: 197. doi:10.4172/2155-6121.1000197

Page 6 of 7

Associations between grass and weed pollen and emergency department visits for asthma among children in Montreal. Environ Res 106: 203-211.

10. D'Amato G, Rottem M, Dahl R, Blaiss M, Ridolo E, et al. (2011) Climate change, migration, and allergic respiratory diseases: an update for the allergist. World Allergy Organ J 4: 120-125.

11. Künzli N, Bridevaux PO, Liu LJ, Garcia-Esteban R, Schindler C, et al. (2009) Traffic-related air pollution correlates with adult-onset asthma among neversmokers. Thorax 64: 664-670.

12. Leung TF, Ko FW, Wong GW (2012) Roles of pollution in the prevalence and exacerbations of allergic diseases in Asia. J Allergy Clin Immunol 129: 42-47.

13. Tosca MA, Ruffoni S, Canonica GW, Ciprandi G (2014) Asthma exacerbation in children: relationship among pollens, weather, and air pollution. Allergo Immunopathol (Madr) 42: 362-368.

14. Dapul-Hidalgo G, Bielory L (2012) Climate change and allergic diseases. Ann Allergy Asthma Immunol 109: 166-172.

15. Delamater PL, Finley AO, Banerjee S (2012) An analysis of asthma hospitalizations, air pollution, and weather conditions in Los Angeles County, California. Sci Total Environ 425: 110-118.

16. Qasem JA, Nasrallah H, Al-Khalaf BN, Al-Sharifi F, Al-Sherayfee A, et al. (2008) Meteorological factors, aeroallergens and asthma-related visits in Kuwait: a 12-month retrospective study. Ann Saudi Med 28: 435-441.

17. Behbehani N, Arifhodzic N, Al-Mousawi M, Marafie S, Ashkanani L, et al. (2004) The seasonal variation in allergic rhinitis and its correlation with outdoor allergens in Kuwait. Int Arch Allergy Immunol 133: 164-167.

18. Thalib L, Al-Taiar A (2012) Dust storms and the risk of asthma admissions to hospitals in Kuwait. Sci Total Environ 433: 347-351.

19. Sabbah I (2010) Impact of aerosol on air temperature in Kuwait. Atmosph Res 97: $303-314$

20. Hoff RM, Christopher SA (2009) Remote sensing of particulate pollution from space: have we reached the promised land? J Air Waste Manag Assoc 59: 645-675.

21. Taylor PE, Flagan RC, Valenta R, Glovsky MM (2002) Release of allergens as respirable aerosols: A link between grass pollen and asthma. J Allergy Clin Immunol 109: 51-56.

22. Halwagy, MH (1994) Airborne pollen of Kuwait City, Kuwait, 1975-87. Grana 33: 333-339

23. Kim H, Bernstein JA (2009) Air pollution and allergic disease. Curr Allergy Asthma Rep 9: 128-133.

24. Cakmak S, Dales RE, Coates F (2012) Does air pollution increase the effect of aeroallergens on hospitalization for asthma? J Allergy Clin Immunol 129 : 228-231.

25. Dowaisan A, Al-Ali S, Khan M, Hijazi Z, Thomson MS, et al. (2000) Sensitization to aeroallergens among patients with allergic rhinitis in a desert environment. Ann Allergy Asthma Immunol 84: 433-438.

26. Al-Dowaisan A, Fakim N, Khan MR, Arifhodzic N, Panicker R, et al. (2004) Salsola pollen as a predominant cause of respiratory allergies in Kuwait. Ann Allergy Asthma Immunol 92: 262-267.

27. Badorrek P, Dick M, Emmert L, Schaumann F, Koch W, et al. (2012) Pollen starch granules in bronchial inflammation. Ann Allergy Asthma Immunol 109: 208-214.

28. Beggs PJ (2010) Adaptation to impacts of climate change on aeroallergens and allergic respiratory diseases. Int J Environ Res Public Health 7: 3006-3021.

29. Bock CH, Jeger MJ, Fitt BDI, Sherington J (1997) Effect of wind of dispersal of oospores of Peronosslerospora sorghi from sorghum. Plant Pathol 46: 439-449

30. National Asthma Education and Prevention Program (2007) Expert Pane Report3: Guidelines for the Diagnosis and Management of Asthma: Full Report Bethesda, MD. Nat Heart Lung Blood Inst.

31. Mireku N, Wang Y, Ager J, Reddy RC, Baptist AP (2009) Changes in weathe and the effects on pediatric asthma exacerbations. Ann Allergy Asthma Immunol 103: 220-224.

32. Weiland SK, Hüsing A, Strachan DP, Rzehak P, Pearce N; ISAAC Phase One Study Group (2004) Climate and the prevalence of symptoms of asthma, allergic rhinitis, and atopic eczema in children. Occup Environ Med 61: 609-
615

33. Li S, Baker PJ, Jalaludin BB, Guo Y, Marks GB, et al. (2014) An Australian national panel study of diurnal temperature range and children's respiratory health. Ann Allergy Asthma Immunol 112(4): 348-353

34. Epton MJ, Martin IR, Graham P, Healy PE, Smith H, et al. (1997) Climate and aeroallergen levels in asthma: a 12 month prospective study. Thorax 52: 528534

35. Abe T, Tokuda Y, Ohde S, Ishimatsu S, Nakamura T, et al. (2009) The relationship of short-term air pollution and weather to ED visits for asthma in Japan. Am J Emerg Med 27: 153-159.

36. Khwarahm N, Dash J, Atkinson PM, Newnham RM, Skjøth CA, et al. (2014) Exploring the spatio-temporal relationship between two key aeroallergens and meteorological variables in the United Kingdom. Int J Biometeorol 58: 529-545.

37. Tashpulatov AS, Clement P, Akimcheva SA, Belogradova KA, Barinova I, et al. (2004) A model system to study the environment-dependent expression of the Bet $\mathrm{v}$ 1a gene encoding the major birch pollen allergen. Int Arch Allergy Immunol 134: 1-9.

38. Sabbah I (2014) Dust and dust storms over Kuwait: Ground -based and satellite observations in preparation

39. Shea KM, Truckner RT, Weber RW, Peden DB (2008) Climate change and allergic disease. J Allergy Clin Immunol 122: 443-453.

40. Lewis SA, Corden JM, Forster GE, Newlands M (2000) Combined effects of aerobiological pollutants, chemical pollutants and meteorological conditions on asthma admissions and A \& E attendances in Derbyshire UK, 1993-96. Clin Exp Allergy 30: 1724-1732.

41. Gauderman WJ, Avol E, Gilliland F, Vora H, Thomas D, et al. (2004) The effect of air pollution on lung development from 10 to 18 years of age. $\mathrm{N}$ Engl $\mathrm{J}$ Med 351: 1057-1067

42. Ko FW, Tam W, Wong TW, Lai CK, Wong GW, et al. (2007) Effects of ai pollution on asthma hospitalization rates in different age groups in Hong Kong Clin Exp Allergy 37: 1312-1319.

43. Athar M, Iqbal M, Beg MU, Al Ajmi D, Al-Muzaini S (1998) Airborne dust from Kuwait in 1991-1992 collected augments peroxidation of cellular membrane lipids and enhances DNA damage. Environ Int 24:205-212

44. Gupta P, Singh S, Kumar S, Choudhary M, Singh V (2012) Effect of dust aerosol in patients with asthma. J Asthma 49: 134-138.

45. Bener A, Abdulrazzaq YM, Al-Mutawwa J, Debuse P (1996) Genetic and environmental factors associated with asthma. Hum Biol 68: 405-414.

46. Barnett AG, Fraser JF, Munck L (2012) The effects of the 2009 dust storm on emergency admissions to a hospital in Brisbane, Australia. Int $\mathrm{J}$ Biometeorol 56: 719-726.

47. http://www.epi.yale.edu/ 


\section{Appendix}

We calculate the back wind trajectories over Kuwait City using the HYSPLIT (Hybrid Single-Particle Lagrangian Integrated Trajectory) model from NOAA. Figure 1 illustrates the 24-hour back trajectory over Kuwait City (marked by the star) on April 18, 2012. The wind directions are shown for heights of 100, 300 and 500 meters. We see that the wind directions are north-westerly.

Figure 1: HYSPLIT model 24-Hour back-trajectories ending at Kuwait represented by star on the 18th of April, 2012

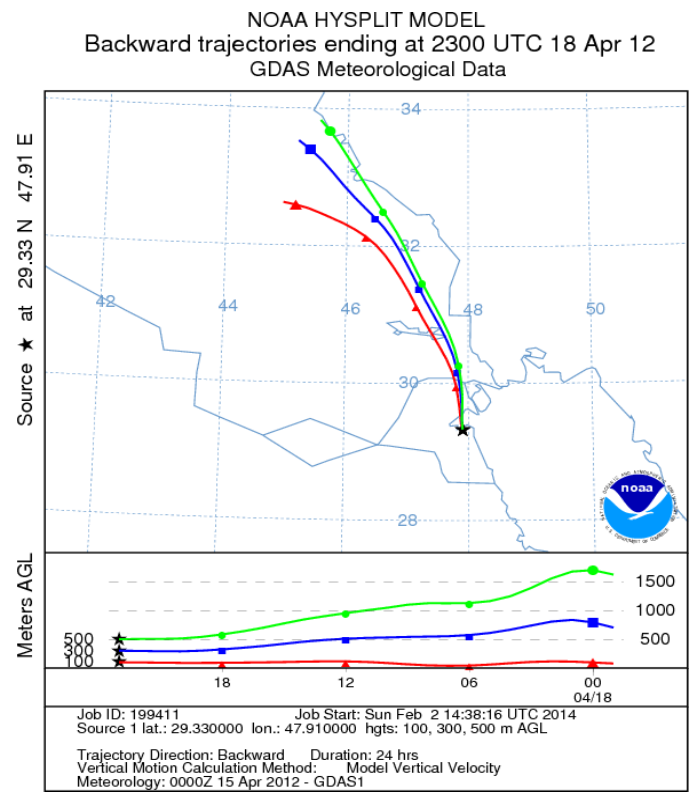

Figure 2: Time series of the daily mean values of: (a) wind speed, (b) relative humidity, (c) visibility, (d) diurnal temperature range.
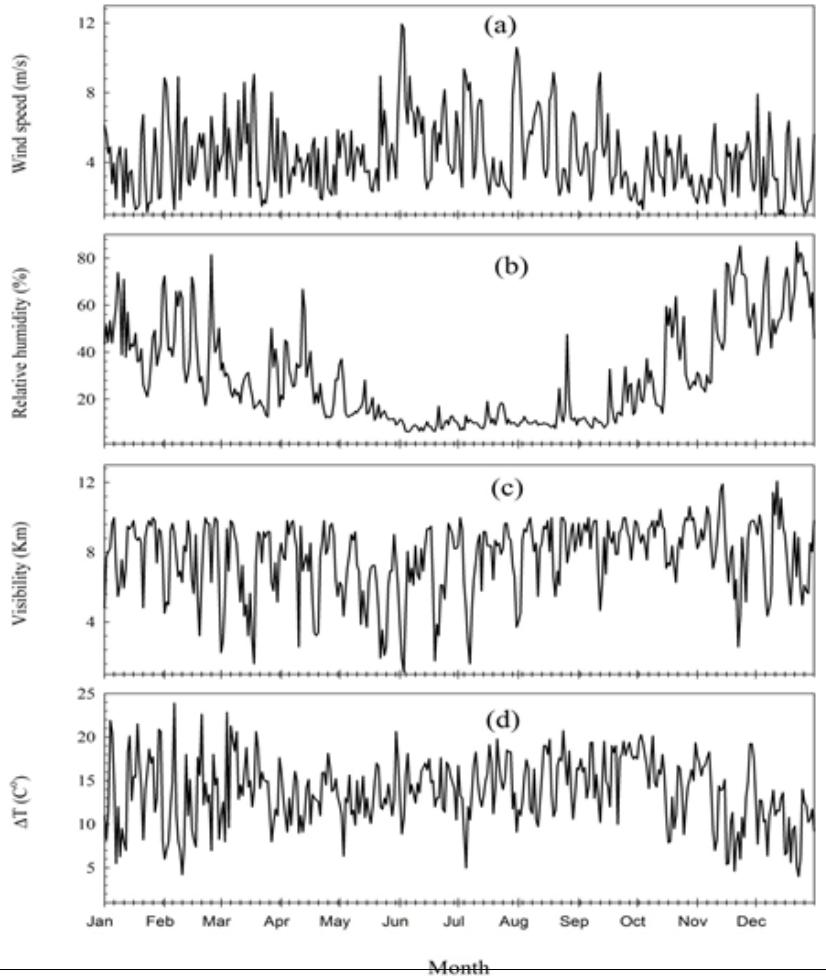